\title{
Impact of Balram Tal Yojna on benefits driven by participant farmers of Dewas district (M.P.)
}

\author{
Mr. Dhirendra Saad*Mr. Chamanlal Sezgaya* Dr. Sandhya Choudhary** \\ \& Dr. V. K. Swarnakar*** \\ *M.Sc. Extension Education Final Year Student 2013 \\ ** Associate Professor Extension Education, College of Agriculture, Indore \\ *** Professor \& Head Extension Education, College of Agriculture, Indore
}

\begin{abstract}
Water is not only the most vital requirement of all living organisms but also provides habitat to a significant production of the earth's biodiversity, representing particularly all groups of plants and animals, ranging from the primitive microorganism to large mammals which pass some or all stages in their life cycle in water. Farm ponds have great potential to improve agricultural water security through the capture, storage, and provision of water for irrigation. Farm ponds can supply a water source for frost protection, recharge of groundwater, and provide a wide range of additional economic and environmental benefits. Keeping in view the importance of water availability, Balram Tal Yojana is being implemented in Madhya Pradesh with a view to hold back maximum quantity of rainwater in agricultural fields, augmenting ground water table and increasing irrigation facility. The aim of this project is to study the impact of the Balram Tal Yojana on beneficiaries in Dewas district of Madhya Pradesh with the sample of 150 respondents of Tonk Khurd block in Dewas district, has been selected purposively for the study because it has highest number of beneficiaries under Balram Tal Yojana in the district. It was apparent from the study that there is clear difference in the overall level of benefits obtain by beneficiaries in respect of crop production components at the time before and after the project. On the whole the data reveled that Balram Tal Yojana had positive impact on improving the crop production components of beneficiaries because after the Yojana the number of beneficiaries had low and medium components found to reduce at the rate of (12.00\%) and (2.00\%) after the project. On the other hand, the number of beneficiaries had high level of component increased at the rate of (14.00\%).
\end{abstract}

\section{Introduction}

Our very own survival on earth essentially depends on two basic resources-soil and water, nature's two valuable gifts to mankind. Mother Nature gives protection to these resources through natural vegetation. This protective shield of land and water are disturbed by our interference, making the soil susceptible to detachment and transportation and run off rain water un-usefulness. A no- care attitude and gross negligence coupled with our ever-increasing needs and demands over the years have taken the problem to a threatening dimension. Farms are undisputedly the most important ecosystems for human welfare. Rainfed agriculture provides nearly $60 \%$ of global food value on $72 \%$ of harvested land. Rainfall variability is an inherent challenge for farming in rainfed agricultural systems. These areas also coincide with many rural smallholder (semi-)subsistence farming systems, with high incidence of poverty and limited opportunities to cope with ecosystem changes. Water for domestic supply and livestock is irregular through temporal water flows and lowering ground water in the landscape. The variable rainfall also results in poor crop water availability, reducing rainfed yields to $25-50 \%$ of potential yields.

All vegetation uses rainwater, whether they are managed such as crops or tree plantations, or if they are natural forests, grasslands and shrubs. Often the ecosystems services from natural vegetation are not fully appreciated for its livelihood support until it is severely degraded, or disappeared, through for example, deforestation. Natural and permanent crop cover has the same effect as many rainwater harvesting interventions. By retaining landscape water flows, increased rainfall infiltration increase growth of vegetation, and decrease soil erosion, surface runoff and incidence flooding. Managing water resources in the landscape is thus management the permanent vegetation cover to enhance biomass production for fibers and energy, to harvest non-timber forest products and to enrich landscape biodiversity. Although forest and trees 'consumes' rainfall, they also safe-guard and generate many ecosystem services for livelihoods and economic good.

Looking to importance of rainwater conservation practices, Government of Madhya Pradesh had started the "Balram Tal" scheme in the year 2007 with the objective to support agricultural activities on a sustainable basis by conservation of rain water in the field. Since 2007 about 8000 beneficiaries have been provided support under the scheme to support agricultural activities on a sustainable basis by conservation of rain water in the field. Since 2007 about 8000 beneficiaries have been provided support under the scheme. The beneficiaries under the scheme are general farmers, small and marginal farmers, SC/ST farmers. It can be said 
that there has been a greater realization and concern about the depleting natural resources like water. As a result of rainwater management on storage/harvesting have been initiated by different development agencies. Various approaches are being tried on pilot basis in rain water restoring and harvesting integrated development projects. The present investigation aims to study the impact of the Balram Tal Yojana on beneficiaries in Dewas district of Madhya Pradesh With following objective-

\section{Objective-}

1- Assessment of Balram Tal Yojana to the beneficiaries with reference to crop production

\section{Review Literature}

Rathore and Kalla (2009) reported that program was playing an important role in the present context because water management along with judicious use of water for raising crop is going to be instrument in sustainable agricultural production in our country and more, especially in Rajasthan. The program has been completed in 1996-97. Keeping this in view the study was conducted to assess impact of NWDP in terms of change in land use pattern, improved water potential, cropping pattern and yield level.

Brij Gopal et.al. (2010) reported that the sustainability of the restoration of water should be ensured through proper monitoring and adaptive management that may be required to achieve the desired goal. Taking into consideration the Ministry of Environment and forests has developed two programs for the restoration of water bodies. Both lakes and wetlands were considered for conservation under this program.

Santini and Peiser (2012) in the case study research, positive environmental impacts were noted by farmers in the district following the implementation of rainwater harvesting structures, related to the surrounding ecology as well as, and importantly for the region, groundwater recharge. In addition, enhanced agricultural production due to the construction of the ponds contributes to on-farm and off-farm employment opportunities and reduces out-migration by making it possible to earn income on the farm.

Rao et.al. (2012) reported that Change detection from different temporal images usually based on reflectance on natural and human activity impact, using integrated GIS, Remote Sensing and image processing technologies enable impact assessment of watershed in desert region.

\section{Material \& Method}

Tonk Khurd block in Dewas district, has been selected purposively for the study because it has highest number of beneficiaries under Balram Tal Yojana in the district. Tonk Khurd block comprises of 59 villages out of which 10 villages were selected on random basis. A comprehensive list of beneficiaries under Balram Tal Yojana in each village was prepared and 150 respondents were selected from the list using proportional method. The researcher required two types of data namely: Primary and Secondary data. The primary data was collected from the respondents by using pre tested interview schedule, questionnaire and observation, while secondary data was collected from the official records, published data, and magazines, journals and other documents. The statistical methods were used in the study depending on the nature of data and type of inference required.

\section{Result}

Assessment of Balram Tal Yojana to the beneficiaries with reference to crop production:-

Assessment of impact or benefits of Balram Tal Yojana as perceived by the beneficiaries in terms of crop production is presented in following table -

Table 1:- Distribution of the beneficiaries according to crop production benefits perceived by them. $(n=150)$

\begin{tabular}{|c|c|c|c|c|c|c|c|c|c|c|}
\hline \multirow{2}{*}{ S.No. } & \multirow{2}{*}{$\begin{array}{l}\text { Benefit derived in terms } \\
\text { of crop production }\end{array}$} & \multicolumn{3}{|c|}{ Before Balram Tal Yojana } & \multicolumn{3}{|c|}{ After Balram Tal Yojana } & \multicolumn{2}{|c|}{$\begin{array}{l}\text { Increase } \\
\text { over before }\end{array}$} & \multirow{2}{*}{ Rank } \\
\hline & & Freq. & $\%$ & $\begin{array}{c}\text { 't' } \\
\text { value }\end{array}$ & Freq. & $\%$ & $\begin{array}{c}\text { 't' } \\
\text { value }\end{array}$ & Freq. & $\%$ & \\
\hline 1. & $\begin{array}{l}\text { Increase in improved crop } \\
\text { production technology }\end{array}$ & 74 & 49.33 & $12.05 *$ & 108 & 72.00 & $19.57^{*}$ & 34 & 22.67 & $\mathbf{V}^{\text {th }}$ \\
\hline 2. & Increase in irrigated area & 73 & 48.67 & $11.89 *$ & 110 & 73.33 & $20.24 *$ & 37 & 24.67 & $I^{\prime \text { th }}$ \\
\hline 3. & $\begin{array}{c}\text { Increase in animal } \\
\text { husbandry enterprise }\end{array}$ & 73 & 48.67 & $11.89 *$ & 112 & 74.67 & $20.96^{*}$ & 39 & 26.00 & II $^{\text {nd }}$ \\
\hline 4. & Increase in cropped area & 74 & 49.33 & $12.05^{*}$ & 111 & 74.00 & $20.59 *$ & 37 & 24.67 & IV $^{\text {th }}$ \\
\hline 5. & $\begin{array}{l}\text { Increase in cultivation of } \\
\text { cash crop area }\end{array}$ & 69 & 46.00 & $11.27 *$ & 113 & 75.33 & $20.61 *$ & 44 & 29.33 & $I^{\text {st }}$ \\
\hline 6. & Increase in productivity & 69 & 46.00 & $11.27 *$ & 107 & 71.33 & $19.26^{*}$ & 38 & 25.33 & III $^{\text {rd }}$ \\
\hline 7. & Overall average & 72 & 48.00 & $36.41 * *$ & 110 & 73.44 & $52.71 * *$ & 38 & 25.33 & \\
\hline
\end{tabular}

* Significant at 5 per cent level 
** Significant at 1 per cent level

It is clear from the table that there was significant difference in each segment of crop production benefits perceived by beneficiaries and overall also in benefit derived by beneficiaries in respect of crop production at both the period i.e. before and after the Balram Tal Yojana. The ' $t$ ' values of each segment of crop production benefits perceived by beneficiaries as well as overall also had shown highly significant difference before and after the Balram Tal Yojana in the level of benefits in respect of crop production by beneficiaries indicating improved the crop production technology and agricultural development respectively.

Thus, it is concluded that there was clear cut difference in the overall increase in crop production components of beneficiaries during before and after the Balram Tal Yojana. The overall crop production component analysis revealed that $(25.33 \%)$ beneficiaries have got additional benefit due to Balram Tal Yojana existing over before crop production components.

The impact of Balram Tal Yojana on crop production components of beneficiaries was also analyzed by distribution of farmers on the basis of low, medium and high benefits obtained at the time of before and after the project. The distribution of beneficiaries as per their benefit obtained in crop production components is presented in following table-

Table 2:- Impact of Balram Tal Yojana on benefit obtained in respect of crop production.

\begin{tabular}{|c|c|c|c|c|c|}
\hline \multicolumn{6}{|c|}{ Level of benefit obtained in respect of crop production } \\
\hline \multicolumn{2}{|c|}{ Before Balram Tal Yojana } & \multicolumn{2}{|c|}{ After Balram Tal Yojana } & \multicolumn{2}{|c|}{$\begin{array}{c}\text { Additional over before Balram Tal } \\
\text { Yojana }\end{array}$} \\
\hline Category & Frequency & Category & Frequency & Frequency & Percentage \\
\hline Low & 52 & Low & 34 & -18 & -12.00 \\
\hline Medium & 50 & Medium & 47 & -3 & -2.00 \\
\hline High & 48 & High & 69 & +21 & +14.00 \\
\hline Total & 150 & Total & 150 & $\mathbf{0}$ & $\mathbf{0}$ \\
\hline 't' value & $36.41 * *$ & 't' value & $52.71 * *$ & & \\
\hline
\end{tabular}

* Significant at 5 per cent level

** Significant at 1 per cent level

The study revealed that Balram Tal Yojana had positive impact on improving the crop production components of beneficiaries. The overall crop production component analysis revealed that $(25.33 \%)$ beneficiaries have got additional benefit due to Balram Tal Yojana existing over before crop production components. It is well known fact that rainfed agriculture provides nearly 60 per cent of food value on more than 70 per cent of harvested land. Rainfall variability is an inherent challenge for farming in most of the area under study with high incidence of lower production and productivity. The Balram Tal Yojana protected the farmers for providing life saving irrigation at the time of scarcity of moisture in the soil which ultimately increase the level of production and productivity. This finding is in conformity with the findings as reported by Achim Steiner (2009), Rathore and Kalla (2009) and Rao et.al. (2012)

\section{Reference}

[1]. Brij Gopal; M.Sengupat; R.Dalwani and S.K.Srivastava (2010). Conservation and Managements of lakes-An Indian perspective. Report Submitted to National River Conservation Directorate, Ministry of Environment and Forests, Government of India, New Delhi.

[2]. Rao,V.Madhava, R.R.Hermon, P.Kesava Rao and T.Phanindra Kumar (2012). Impact Assessment of Watershed in Desert Region. International Archives of the Photogrammetry, Remote Sensing and Spatial Information Sciences. 39:327-331.

[3]. Rathore,R.S. and P.N.Kalla (2009). Impact of National Watershed Development Programme (NWDP) on agricultural production in tribal area of Southern Rajasthan. Editorial report Department of Extension Education, Institute of Agricultural Sciences, Banaras Hindu University, Varanasi, (India).

[4]. Santini,G. and L.Peiser (2012). Decentralized Rainwater Harvesting in Madhya Pradesh. Agriculture Water Management Business proposal Document. 